\title{
Indeterminacy with No-Income-Effect Preferences and Sector-Specific Externalities*
}

\author{
Jang-Ting $\mathrm{Guo}^{\dagger}$ \\ University of California, Riverside \\ Sharon G. Harrison ${ }^{\ddagger}$ \\ Barnard College, Columbia University
}

July 9,2008

\begin{abstract}
We examine a two-sector real business cycle model with sector-specific externalities in the production of distinct consumption and investment goods. In addition, the household utility is postulated to exhibit no income effect on the demand for leisure. Unlike in the one-sector counterpart, we show that equilibrium indeterminacy can result with sufficiently high returns-to-scale in the production of investment goods. We also find that the smaller the labor supply elasticity, the lower the threshold level of returns-to-scale needed for generating indeterminacy and sunspots. This finding turns out to be exactly the opposite of that in all existing RBC-based indeterminacy studies.
\end{abstract}

Keywords: Indeterminacy, Income Effect, Sector-Specific Externalities.

JEL Classification: E30, E32.

\footnotetext{
*We thank Nir Jaimovich, Qinglai Meng and Chong-Kee Yip for helpful comments and suggestions. Of course, all remaining errors are our own.

${ }^{\dagger}$ Department of Economics, 4128 Sproul Hall, University of California, Riverside, CA, 92521, (951) 827-1588, Fax: (951) 827-5685, e-mail: guojt@ucr.edu.

${ }^{\ddagger}$ Corresponding Author. Barnard College, Department of Economics, 3009 Broadway, New York, NY 10027, (212) 854-3333, Fax: (212) 854-8947, e-mail: sh411@columbia.edu.
} 


\section{Introduction}

Starting with the work of Benhabib and Farmer (1994) and Farmer and Guo (1994), there is now an extensive macroeconomic literature that explores indeterminacy and sunspots in the real business cycle (RBC) model. ${ }^{1}$ The original Benhabib-FarmerGuo one-sector economy, with a Cobb-Douglas production function and sufficiently strong increasing returns, displays multiple equilibria and belief-driven business cycle fluctuations when the separable household utility is logarithmic in consumption and convex in hours worked. More recently, Meng and Yip (2008) and Jaimovich (2008) (hereafter MYJ) have shown that a one-sector RBC model, instead with nonseparable preferences, always exhibits saddle-path stability and equilibrium uniqueness when there is no income effect on the demand for leisure, regardless of the degree of aggregate returns-to-scale in production. MYJ's result illustrates the critical importance of the income effect associated with the household's labor supply decision in generating indeterminacy and sunspots within one-sector RBC models.

In this paper, we build upon MYJ's analyses and examine the quantitative interrelations between equilibrium indeterminacy and the no-income-effect utility function in a two-sector RBC model. Distinct consumption and investment goods are produced with sector-specific productive externalities a la Benhabib and Farmer (1996) and Harrison (2001). Our main findings are summarized as follows. First, unlike in MYJ's one-sector model, our two-sector economy may exhibit an indeterminate steady state, and thus a continuum of stationary perfect-foresight equilibria, when sufficiently strong externalities are present. Intuitively, in order for equilibrium indeterminacy to occur in any dynamic general equilibrium macroeconomic model, the associated first-order conditions must continue to hold when there is a change in non-fundamental expectations. In particular, the household's intertemporal euler equation equates the shadow value of capital sacrificed this period in order to consume - this period's marginal utility of consumption - to the discounted utility value of capital gained next period - its gross rate of return weighted by the marginal utility of next period's consumption. Therefore, upon the expectation of a higher

\footnotetext{
${ }^{1}$ See Benhabib and Farmer (1999) for an excellent survey. With the noted exceptions of Benhabib and Nishimura (1998), and Benhabib, Meng and Nishimura (2000), most studies in this literature postulate constant returns-to-scale at the individual firm level. We also maintain this assumption throughout our analysis.
} 
return on capital in the future, agents will consume and work more next period. In the MYJ economy, this expectation cannot be self-fulfilled, because any increase in labor hours that may raise the gross return on capital will actually decrease its net return by reducing the marginal utility of consumption. In our model, however, next period's net return on capital also depends positively on its price, which increases when future consumption rises. Therefore, the same increase in hours worked can in fact lead to the anticipated hike in the return on capital.

Second, we find that a necessary and sufficient condition for indeterminacy and sunspots in our model is sufficiently strong increasing returns-to-scale in the investment sector. The intuition for this result is the same as in the separable preference set-up of Harrison (2001): when agents anticipate that the return on capital will increase tomorrow, they need incentive to give up consumption today for more capital accumulation. As long as they will be rewarded with productive investment, in the form of sufficient increasing returns in that sector, it will be worthwhile for them to do so.

Third, and perhaps most surprising, the degree of increasing returns-to-scale required for our model to exhibit multiple equilibria increases with the household's labor supply elasticity. In other words, the smaller the labor supply elasticity, the lower the threshold level of investment externalities needed to produce equilibrium indeterminacy. This finding is exactly the opposite of that in all existing RBC-based indeterminacy studies, where an infinitely elastic labor supply is often adopted. The reason is that, to fulfill agents' optimistic expectations in our model economy, and satisfy the household's intertemporal euler equation, movements in labor hours across time periods must be kept small. A large increase in hours worked can reduce the overall future return on capital by reducing next period's marginal utility of consumption. Therefore, the smaller the labor supply elasticity, the easier indeterminacy and sunspots are to obtain, in that lower returns-to-scale in production are needed. In a calibrated version of our model, we find that equilibrium indeterminacy is rendered impossible when the labor supply elasticity is higher than 2 .

The remainder of the paper is organized as follows. Section 2 describes the model. Section 3 examines the model's local stability properties and presents quantitative results. Section 4 concludes. 


\section{The Economy}

Our model incorporates a no-income-effect preference into the discrete-time twosector real business cycle (RBC) model as in Harrison (2001). Households live forever, and derive utility from consumption and leisure. The production side of the economy consists of two sectors, consumption and investment. For expositional simplicity, firms in each sector produce output using identical technologies, but subject to distinct sector-specific external effects. We assume that there are no fundamental uncertainties present in the economy.

\section{$2.1 \quad$ Firms}

In the consumption sector, output is produced by competitive firms using the following technology:

$$
Y_{c t}=A_{t} K_{c t}^{\alpha} L_{c t}^{1-\alpha}, 0<\alpha<1,
$$

where $K_{c t}$ and $L_{c t}$ are the capital and labor inputs used in the production of consumption goods. In addition, $A_{t}$ represents productive externalities that each individual firm takes as given, and is specified as

$$
A_{t}=\left[\bar{K}_{c t}^{\alpha} \bar{L}_{c t}^{1-\alpha}\right]^{\theta_{c}}, \theta_{c} \geq 0,
$$

where $\bar{K}_{c t}$ and $\bar{L}_{c t}$ denote the economy-wide average capital and labor used in producing the consumption good, and $\theta_{c}$ measures the degree of sector-specific externalities in the consumption sector.

Similarly, investment goods are produced by competitive firms using the technology

$$
Y_{I t}=B_{t} K_{I t}^{\alpha} L_{I t}^{1-\alpha}, \text { where } B_{t}=\left[\bar{K}_{I t}^{\alpha} \bar{L}_{I t}^{1-\alpha}\right]^{\theta_{I}} .
$$

Here, $K_{I t}$ and $L_{I t}$ are capital and hours worked in the investment sector, and $B_{t}$ represents a productive externality that is an increasing function of the economy-wide average levels of productive capital and labor devoted to producing investment goods. As in Harrison (2001), the degree of sector-specific externalities in the investment sector, denoted as $\theta_{I}$, is allowed to differ from that for consumption $\theta_{c}$.

Under the assumptions that factor markets are perfectly competitive and that capital and labor inputs are perfectly mobile across the two sectors, the first-order conditions for the firms' profit maximization problems are 


$$
\begin{aligned}
r_{t} & =\frac{\alpha Y_{c t}}{K_{c t}}=p_{t} \frac{\alpha Y_{I t}}{K_{I t}}, \\
w_{t} & =\frac{(1-\alpha) Y_{c t}}{L_{c t}}=p_{t} \frac{(1-\alpha) Y_{I t}}{L_{I t}},
\end{aligned}
$$

where $r_{t}$ is the rental rate of capital, $w_{t}$ is the real wage rate, and $p_{t}$ denotes the price of investment relative to consumption goods.

\subsection{Households}

There is a unit measure of identical infinitely-lived households, each with one unit of time endowment and maximizes its present discounted lifetime utility:

$$
\sum_{t=0}^{\infty} \beta^{t}\left[\log \left(C_{t}-\frac{\Lambda L_{t}^{1+\chi}}{1+\chi}\right)\right], 0<\beta<1, \chi \geq 0 \quad \text { and } \Lambda>0
$$

where $C_{t}$ and $L_{t}$ are the representative household's consumption and hours worked, $\beta$ is the discount factor, and $\chi$ is the inverse of the wage elasticity of labor supply. The budget constraint faced by the representative household is

$$
C_{t}+p_{t} I_{t}=Y_{t}=r_{t} K_{t}+w_{t} L_{t}
$$

where $I_{t}$ is gross investment, $Y_{t}$ is $G D P$ and $K_{t}$ is the household's capital stock. The law of motion for the capital stock is given by

$$
K_{t+1}=(1-\delta) K_{t}+I_{t}, K_{0} \text { given, }
$$

where $\delta \in(0,1)$ is the capital depreciation rate.

The first-order conditions for the household's optimization problem are

$$
\begin{gathered}
\Lambda L_{t}^{\chi}=w_{t}, \\
C_{t+1}-\frac{\Lambda L_{t+1}^{1+\chi}}{1+\chi}=\beta\left[C_{t}-\frac{\Lambda L_{t}^{1+\chi}}{1+\chi}\right]\left[\frac{r_{t+1}+(1-\delta) p_{t+1}}{p_{t}}\right] \\
\lim _{t \rightarrow \infty} \beta^{t} \frac{K_{t+1}}{C_{t}}=0,
\end{gathered}
$$


where (9) equates the slope of the household's indifference curve to the real wage. Note that this equation illustrates the lack of income effect associated with the household's labor supply decision, as $C_{t}$ is missing. It follows that the income elasticity of intertemporal substitution in hours worked (or leisure) is zero. Moreover, (10) is the standard consumption Euler equation, and (11) is the transversality condition.

Our goal is to examine the local stability properties of the steady state of the above model economy. Before proceeding further, it is useful to obtain an understanding of the implications of incorporating the no-income-effect utility function. In particular, Benhabib and Farmer (1994, 1996), Farmer and Guo (1994) and Harrison (2001), among many others, adopt standard separable preferences

$$
U\left(C_{t}, L_{t}\right)=\log \left(C_{t}\right)-\frac{A L_{t}^{1+\chi}}{1+\chi}, \quad \chi \geq 0 \quad \text { and } A>0
$$

and the resulting first-order condition for the choice of labor supply is

$$
A L_{t}^{\chi}=\frac{w_{t}}{C_{t}}
$$

Here, the income and substitution effects can be separated. An increase in the real wage, holding consumption constant, will raise $L_{t}$ - the substitution effect. An increase in consumption, however, leads to a fall in $L_{t}$ - the income effect. In all RBC-based models, the real wage and consumption are procyclical: they move together with output. In addition, in these models, the substitution effect dominates, so that when $w_{t}$ and $C_{t}$ increase, so does $L_{t}$.

In our model, the first-order condition for hours worked is equation (9), where there is no income effect to counteract the substitution effect. As a result, when the real wage (and consumption) increases, $L_{t}$ rises by more than that in (13).

\subsection{Equilibrium and Local Dynamics}

We focus on symmetric perfect-foresight equilibria which consist of a set of prices $\left\{p_{t}, r_{t}, w_{t}\right\}_{t=0}^{\infty}$ and quantities $\left\{C_{t}, L_{t}, K_{t+1}\right\}_{t=0}^{\infty}$ that satisfies the household's and firms' first-order conditions. Moreover, the aggregate consistency condition requires that $K_{c t}=\bar{K}_{c t}, L_{c t}=\bar{L}_{c t}, K_{I t}=\bar{K}_{I t}$ and $L_{I t}=\bar{L}_{I t}$, for all $t$. The equalities of demand by households and supply by firms in the consumption and investment sectors are given by $C_{t}=Y_{c t}$ and $I_{t}=Y_{I t}$. Finally, both the capital and labor markets clear 
whereby

$$
\begin{aligned}
K_{c t}+K_{I t} & =K_{t}, \\
L_{c t}+L_{I t} & =L_{t} .
\end{aligned}
$$

It is straightforward to show that our model possesses a unique interior steady state. We then take log-linear approximations to the equilibrium conditions in a neighborhood of this steady state to obtain the following dynamic system:

$$
\left[\begin{array}{l}
\hat{K}_{t} \\
\hat{p}_{t}
\end{array}\right]=J\left[\begin{array}{l}
\hat{K}_{t+1} \\
\hat{p}_{t+1}
\end{array}\right], \hat{K}_{0} \text { given }
$$

where hat variables denote percentage deviations from their steady-state values, and $J$ is the Jacobian matrix of partial derivatives of the transformed dynamic system. The model exhibits saddle-path stability and equilibrium uniqueness when one eigenvalue of $J$ lies inside and the other outside the unit circle. When both eigenvalues are outside the unit circle, the steady state is indeterminate and thus a sink. When both eigenvalues are inside the unit circle, the steady state becomes a totally unstable source.

\section{$3 \quad$ Local Stability Properties}

As discussed earlier, MYJ show that equilibrium indeterminacy cannot result in the one-sector version of the above model. This section quantitatively examines the local stability properties in our two-sector setting. It turns out that the first result clearly distinguishes our model from MYJ.

Result 1: In sharp contrast to MYJ, indeterminate equilibria result in our model with sufficiently high returns-to-scale.

The exact meaning of "sufficiently high" will be made clear below. As demonstrated by MYJ, in the one-sector version of our model, equilibrium indeterminacy is not possible regardless of the degree of aggregate returns-to-scale in production. What is different here? The answer lies in recalling the intratemporal first-order condition with respect to labor supply, (9), and comparing the intertemporal euler 
equations from the two models. After rearranging (10), ours is

$$
\frac{C_{t+1}-\frac{\Lambda L_{t+1}^{1+\chi}}{1+\chi}}{C_{t}-\frac{\Lambda L_{t}^{1+\chi}}{1+\chi}}=\beta\left[\frac{r_{t+1}+(1-\delta) p_{t+1}}{p_{t}}\right],
$$

and its counterpart in the one-sector version is

$$
\frac{C_{t+1}-\frac{\Lambda L_{t+1}^{1+\chi}}{1+\chi}}{C_{t}-\frac{\Lambda L_{t}^{1+\chi}}{1+\chi}}=\beta\left[r_{t+1}+(1-\delta)\right] .
$$

In order for equilibrium indeterminacy to occur in either economy, the relevant euler equation must be satisfied when there is a change in non-fundamental expectations. For example, starting from the steady state, upon an expected increase in the marginal return on capital, agents sacrifice consumption this period in order to invest more today. Therefore, $C_{t}$ falls while $k_{t+1}$. increases. This enables agents to consume more in period $t+1: C_{t+1}$ rises. However, due to the lack of income effect, as seen in $(9), L_{t}$ remains unchanged, while the increase in $k_{t+1}$ leads to a rise in $L_{t+1}$, via the firms' labor demand. The latter has two counteracting effects in the euler equations. First, the bigger (smaller) the increase in $L_{t+1}$, the smaller (bigger) the increase of the left-hand side. Second, the bigger (smaller) the increase in $L_{t+1}$, the larger (smaller, or a decrease may occur) the rise in the real interest rate, $r_{t+1}$. In MYJ's one-sector model with (18), these two effects render the equality impossible. With $C_{t}$ falling and $C_{t+1}$ rising, a large increase in $L_{t+1}$ is needed for $r_{t+1}$ and the right-hand side to rise. But this would then decrease the left-hand side. At the same time, if the increase in $L_{t+1}$ is small, keeping the left-hand side high, $r_{t+1}$ and the right-hand side cannot rise enough.

However, in our two-sector model with (17), movements of productive resources affect the relative price of investment. In particular, as Benhabib and Farmer (1996) and Harrison (2001) have explained, due to the presence of increasing returns-to-scale, the social PPF showing the trade-off between consumption and investment is convex to the origin. This implies that the shifting of resources towards the production of a good raises the marginal product of each factor used in its production, and lowers the price of that good. Hence, upon agents' optimistic expectations, the shift away from consumption in period $t$ lowers the relative price of investment, $p_{t}$; and the shift toward consumption in period $t+1$ increases $p_{t+1}$. It follows that small movements in 
$L_{t+1}$ that increase the left-hand side of (17) can also lead to a rise in the right-hand side even though the marginal product of capital may not rise (or rise enough).

Our second result is reminiscent of Harrison (2001):

Result 2: A necessary and sufficient condition for equilibrium indeterminacy is a sufficiently high value of $\theta_{I}$, the degree of productive externality in investment.

The reason is the same as in Harrison (2001). When agents expect the return on capital to increase tomorrow, they need incentive to give up consumption today for more capital accumulation. As long as they will be rewarded with productive investment, in the form of increasing returns in that sector, it will be worthwhile for them to do so. In other words, it is the return on capital that agents care about, and so their expectation of its increase is fulfilled when there are sufficiently high returns-to-scale in the production of investment goods.

Result 2 allows us to set $\theta_{c}=0$ for the following quantitative analyses. We calibrate the rest of the model economy using parameter values consistent with postwar US data. Each period in the model is taken to be one quarter. As is common in the real business cycle literature, the capital share of national income, $\alpha$, is chosen to be 0.3 ; the discount factor, $\beta$, is set equal to 0.99 ; and the capital depreciation rate, $\delta$, is fixed at 0.025 . We then examine the model's local stability properties for different combinations of $\chi$ and $\theta_{I}$. In each parametric configuration, the preference parameter $\Lambda$ is set to ensure that the steady-state labor hours is equal to $1 / 3$. Figure 1 illustrates the local stability properties of our model, and our third result:

Result 3: Below $\chi=0.5$ (labor supply elasticity above 2), equilibrium indeterminacy is not possible (not shown). ${ }^{2}$ However, as long as $\chi \geq 0.5$, a sufficiently high externality in investment results in local indeterminacy. We denote the threshold value of the externality $\theta_{I}^{\min }$.

The intuition for this result lies in reconsidering (17). Repeating the experiment, starting from the steady state, upon an expected increase in the marginal return on capital, agents will invest more today. $C_{t}$ and $p_{t}$ fall; and $k_{t+1 .}, C_{t+1}$ and $p_{t+1}$ increase.

\footnotetext{
${ }^{2}$ For $\chi<.5$, the equilibrium can be either determinate or unstable. In particular, for each $\chi<.5$, the model's steady state is a saddle point below a critical value of $\theta_{I}$, and is a source above it. This critical value of $\theta_{I}$ increases with $\chi$.
} 
With no income effect, $L_{t}$ remains unchanged, but $w_{t+1}$ and $L_{t+1}$ increase, which in turn raises the right-hand side of the euler equation, (17). Therefore, the left-hand side must increase equally; and this requires a small increase in $L_{t+1}$. Looking again at (9), we see that the higher the $\chi$ (or the lower the labor supply elasticity), the smaller the increase in $L_{t+1}$. It turns out that for $\chi<0.5$, the labor supply elasticity is "too high", thus $L_{t+1}$ rises too much. For $\chi \geq 0.5$, and lower labor supply elasticity, a smaller change in $L_{t+1}$ results.

The above finding also helps us to understand our fourth result, which explains the negative slope of the curve in Figure 1:

Result 4: Equilibrium indeterminacy becomes easier to obtain, in the sense that lower investment externalities are needed, as the labor supply elasticity falls. That is, when $\chi$ increases, $\theta_{I}^{\min }$ decreases $\left(\frac{\partial \theta_{I}^{\min }}{\partial \chi}<0\right)$.

This result is exactly the opposite of that in every other RBC-based indeterminacy model. ${ }^{3}$ What it means is that as the household's labor supply becomes less elastic, lower returns-to-scale in production are required for equilibrium indeterminacy. Intuitively, just like with $\chi$, the change in $L_{t+1}$ falls as $\theta_{I}$ increases. This is because higher returns-to-scale imply that the same output gain, and increase in the real wage, can be achieved with a smaller rise in inputs. Therefore, since increases in both $\chi$ and $\theta_{I}$ lead to smaller changes in $L_{t+1}$, the higher the $\chi$, the lower the returns-to-scale needed to keep the increase in $L_{t+1}$ small enough to satisfy (17).

\section{Conclusion}

This paper extends MYJ's analyses, and examines the stability effect of incorporating no-income-effect preferences into a two-sector real business cycle model with sectorspecific externalities. While indeterminacy and sunspots are impossible in the MYJ one-sector economy, their result is overturned here because movements of factors of production affect the relative price of investment in our two-sector setting. In addition, due to the non-separability of consumption and leisure in the household's utility, the key to generating equilibrium indeterminacy is small movements in labor

\footnotetext{
${ }^{3}$ For example, Benhabib and Farmer (1996, p 433), demonstrate the positive relationship between $\chi$ and $\theta_{I}^{\min }$ in a two-sector model with the separable utility function (12).
} 
supply. Hence, indeterminacy and sunspots are easier to obtain with a lower labor supply elasticity. In terms of possible extensions, it would be worthwhile to examine the robustness of our results under a generalized non-separable utility a la Jaimovich (2008) that allows for different degrees of income effect on the demand for leisure. We plan to pursue this research project in the future. 


\section{References}

[1] Benhabib, J. and R.E.A. Farmer, 1994, Indeterminacy and Increasing Returns, Journal of Economic Theory 63, 19-41.

[2] Benhabib, J. and R.E.A. Farmer, 1996, Indeterminacy and Sector-Specific Externalities, Journal of Monetary Economics 37, 421-444.

[3] Benhabib, J. and R.E.A. Farmer, 1999, Indeterminacy and Sunspots in Macroeconomics, in J. Taylor and M. Woodford, eds., Handbook of Macroeconomics, Vol. 1, North Holland: Amsterdam, 387-448.

[4] Benhabib, J., Q. Meng and K. Nishimura, 2000, Indeterminacy Under Constant Returns to Scale in Multisector Economies, Econometrica 68, 1541-1548.

[5] Benhabib, J. and K. Nishimura, 1998, Indeterminacy and Sunspots with Constant Returns, Journal of Economic Theory 81, 58-96.

[6] Farmer, R.E.A. and J.T. Guo, Real Business Cycles and the Animal Spirits Hypothesis, Journal of Economic Theory 63, 42-72.

[7] Harrison, S.G., 2001, Indeterminacy in a Model with Sector-Specific Externalities, Journal of Economic Dynamics and Control 25, 747-764.

[8] Jaimovich, N., 2008, Income Effects and Indeterminacy in a Calibrated OneSector Growth Model, Journal of Economic Theory, forthcoming.

[9] Meng, Q. and C.K. Yip, 2008, On Indeterminacy in One-Sector Models of the Business Cycle with Factor-Generated Externalities, Journal of Macroeconomics 30, $97-110$. 
Figure 1: Local Stability Properties

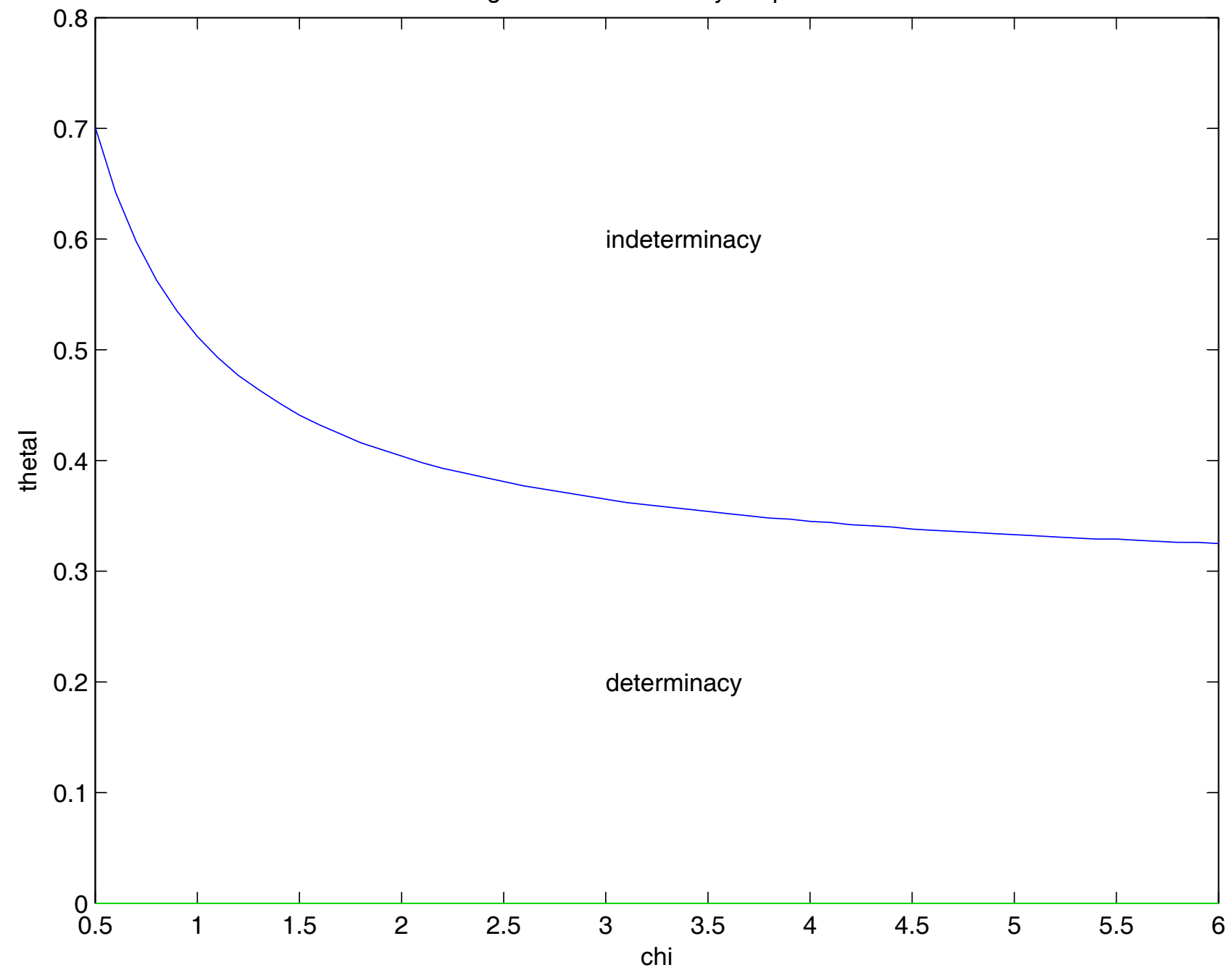

